\title{
Normal Weight Estonian Prepubertal Boys Show a More Cardiovascular-Risk-Associated Adipose Tissue Distribution than Austrian Counterparts
}

\author{
Sandra J. Wallner-Liebmann, ${ }^{1}$ Reinhard Moeller, ${ }^{2}$ Renate Horejsi, ${ }^{2}$ Toivo Jürimäe, ${ }^{3}$ \\ Jaak Jürimäe, ${ }^{3}$ Jarek Mäestu, ${ }^{3}$ Priit Purge, ${ }^{3}$ Meeli Saar, ${ }^{3}$ Erwin Tafeit, ${ }^{2}$ Petra Kaimbacher, ${ }^{1}$ \\ Renate Kruschitz, ${ }^{1}$ Daniel Weghuber, ${ }^{4}$ Wolfgang J. Schnedl, ${ }^{5}$ and Harald Mangge ${ }^{6}$ \\ ${ }^{1}$ Center of Molecular Medicine, Institute of Pathophysiology and Immunology, Medical University of Graz, Heinrichstraße 31a, \\ 8010 Graz, Austria \\ ${ }^{2}$ Center of Physiological Medicine, Institute of Physiological Chemistry, University of Graz, 8010 Graz, Austria \\ ${ }^{3}$ Faculty of Exercise and Sports Sciences, Center of Behavioural and Health Sciences, University of Tartu, 50090 Tartu, Estonia \\ ${ }^{4}$ Department of Pediatrics, Paracelsus Private Medical University of Salzburg, 5020 Salzburg, Austria \\ ${ }^{5}$ Practice for General Internal Medicine, Bruck a.d.M., 8600 Graze, Austria \\ ${ }^{6}$ Clinical Institute for Medical and Chemical Laboratory Diagnosis, Medical University of Graz, 8010 Graz, Austria
}

Correspondence should be addressed to Sandra J. Wallner-Liebmann; sandra.wallner@medunigraz.at

Received 4 December 2012; Accepted 21 December 2012

Academic Editors: J. J. Gleysteen, H. Gordish-Dressman, and D. Micic

Copyright (C) 2013 Sandra J. Wallner-Liebmann et al. This is an open access article distributed under the Creative Commons Attribution License, which permits unrestricted use, distribution, and reproduction in any medium, provided the original work is properly cited.

\begin{abstract}
Objective. Risk phenotypes for cardiovascular disease (CVD) differ markedly between countries, like the reported high difference in CVD mortality in Austria and Estonia. Hitherto, the goal of this study was to find out risk profiles in body fat distribution yet present in childhood, paving the way for later clinical end points. Methods. he subcutaneous adipose tissue (SAT) distribution patterns in 553 Austrian (A) and Estonian (E) clinically healthy normal weight boys aged $11.1( \pm 0.8)$ years were analysed. We applied the patented optical device Lipometer which determines the individual subcutaneous adipose tissue topography (SAT-Top). Results. Total body fat did not differ significantly between $\mathrm{E}$ and A boys. A discriminant analysis using all Lipometer data, BMI, and the total body fat (TBF) yielded $84.6 \%$ of the boys correctly classified in Estonians and Austrians by 9 body sites. A factor analysis identified the SAT distribution of E as critically similar to male adult patients with coronary heart disease (CHD). Conclusions. We show in normal weight Estonian boys a highly significant decreased fat accumulation on the lower body site compared to age matched Austrian males. This SAT-Top phenotype may play an important role for the increased cardiovascular risk seen in the Estonian population.
\end{abstract}

\section{Introduction}

The risk for populational diseases differs markedly between geographic regions and countries, as, for example, the reported greater rate of cardiovascular mortality in Estonia compared to Austria. The latest age standardised ischemic heart disease (IHD) mortality data per 100000 population are for Austria 80,68, while for Estonia 254,25 [1].

So far, the studies investigating cardiovascular disease (CVD) risk factors focused on adult obesity and associated metabolic disorders. However, for the assessment of populational health, it is of outmost interest to gain a better insight in the pediatric roots of CVD.

Although it is well established that obesity and the subcutaneous adipose tissue (SAT) phenotype are essentially involved in CVD risk, little information exists about risk phenotypes in prepubertal obese children.

Notably, the prevalence of childhood obesity increased 4 -fold during the last 20 years [2], and this represents a strong risk factor for obesity of adulthood [3]. The SAT 


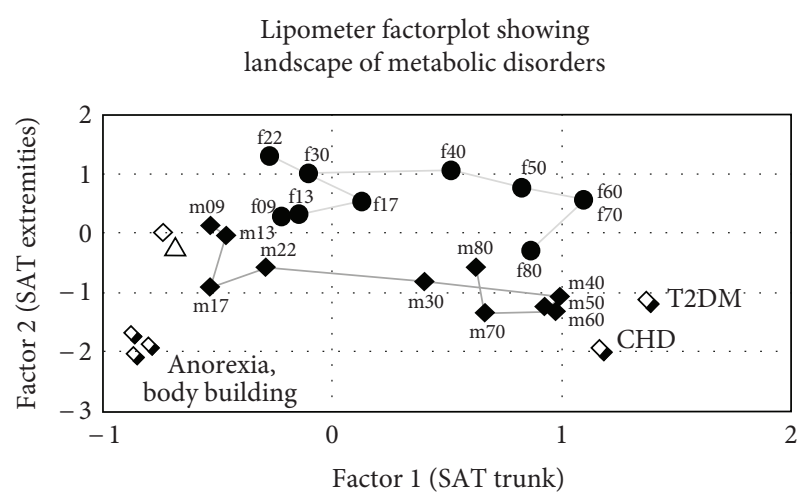

FIGURE 1: Factor analysis condenses the subcutaneous adipose tissue topography (SAT-Top) information at the trunk and the body sites at the extremities into a two-dimensional plot, where the position of each subject group is located (Austrian boys: rhombus; Estonian boys: triangle).

phenotype in children is of growing interest for later on CVD risk. An improved understanding of individual subcutaneous body fat distribution and body composition in children may essentially support the development of effective preventive strategies [4-7] for the metabolic syndrome and CVD [7-11].

Various methods to evaluate body composition in children exist. Due to the necessary technical equipment, some of these methods are very expensive besides being inappropriate for the use in field studies. The optical device Lipometer (EU Pat. no. 0516251) was developed to generate noninvasive, quick, accurate, and safe measurements of a monolayer of subcutaneous adipose tissue (SAT) at any given site of the human body. Technical features and validation results were based on computed tomography as reference system [12, 13]. The Lipometer allows the measurement of subcutaneous fat distribution and the determination of the subcutaneous adipose tissue topography (SAT-Top). Previous results using the Lipometer to determine the SAT-Top emphasize the importance of describing subcutaneous adipose tissue in adult obesity and metabolic syndrome as well as during childhood and adolescence [14-17].

Marked differences of mortality rates were seen between EU member states as analysed by the topology of male mortality [18]. This analysis yielded six groups of member states. Austria belongs to "type 1" with an almost average mortality, and Estonia is presented in "type 5" with high excess mortality from 20 to 64 years. Thus, we hypothesize herein the presence of high risk cardiovascular SAT-Top phenotype already present in Estonian children.

This study analysed the subcutaneous body fat distribution in a sample of 553 clinically healthy male prepubertal boys aged around 11 years living in Austria or Estonia.

\section{Subjects and Methods}

2.1. Subjects. The participants and their parents consented to the study after receiving a thorough explanation of the declaration of consent. The procedure chosen was in accordance with the Declaration of Helsinki and the local ethics committee recommendations. Height, weight, and SAT-Top were measured in 553 boys aged $11,1( \pm 0,8)$ years. Since there is a peak of fat mass in boys at the age of 11 years, we recruited individuals aged 10,0 to 12,0 years.

The participants were recruited in different schools and outpatient clinics from urban areas as well as in the local University Clinic for Pediatrics and Adolescent Medicine in Graz, Austria, and Tartu, Estonia. In Graz, boys of similar age were recruited from the STYrian Juvenile Obesity Study, which were designed to investigate early atherosclerosis and metabolic disorders in obese juveniles [19]. In Estland, boys were recruited from a running preventive study on obesity and exercise. None of the studied children suffered from endocrine or syndromal disorders or were on any medication. Height was measured using a stadiometer (SECA220, Hamburg, Germany). Body mass was measured to the nearest $0.01 \mathrm{~kg}$ using calibrated electronic scales (Soehnle 7700, Murrhardt, Germany).

Degree of overweight was calculated as body mass index (BMI). Height was measured to the nearest centimeter. Weight was measured in underwear to the nearest $0.1 \mathrm{~kg}$ using a calibrated balance scale. We used Box-Cox transformation to calculate BMI as a measure for degree of overweight due to the skewness of the BMI distribution [20]. Overweight was defined by a BMI above the 90th percentile for German children [21]. All children were also overweight according to the International Task Force for Childhood Obesity [22].

In addition to the reported group of Austrian and Estonian boys, we included the age development of 960 healthy controls aged from $9(\mathrm{~m} 09)$ to 80 years $(\mathrm{m} 80)$ who were recruited from health and fitness checks in Austria and Austrian male adult patients with type 2 diabetes (T2DM), coronary heart disease (CHD), and persons with extremely thin fatty tissue layers (anorexia and body builders) (published in $[15,23]$ for visual comparison in a two-dimensional factor plot).

\subsection{Measurement of Subcutaneous Adipose Tissue Topography} (SAT-Top). Measurements of SAT thickness were performed by means of a patented optical device (EU Pat. no. 0516251) on 15 anatomically well-defined body sites distributed from neck to calf on the right and left side of all children and then averaged for both body sides. The sensor head of the Lipometer, that is held perpendicular to the measurement site, consists of a light source of light-emitting diodes $(\lambda=$ $660 \mathrm{~nm}$, light intensity $3.000 \mathrm{mcd}$ ) and a photodetector that measures the corresponding light intensities that are back scattered in the SAT. Calibration and evaluation were done using computer tomography (CT) as the reference method.

To obtain the Lipometer measurement values and the corresponding absolute values of $\mathrm{CT}$ for subcutaneous adipose tissue thickness, CT scans at defined levels (upper abdomen, lower abdomen, and extremities) were made by a third generation CT scanner (Somatom DR3, Somatom DHR, SIEMENS, Erlangen, Germany). These levels were marked, and Lipometer measurements were performed step by step around the body circumferences. Thus, a set of datapoints of both, Lipometer light patterns and corresponding absolute 
TABLE 1: Descriptive characteristics (mean \pm SD) and subcutaneous adipose tissue-topography (SAT-Top) measurements (the thickness of subcutaneous adipose tissue in $\mathrm{mm}$ at 15 specified body sites: from 1-neck to 15-calf) medians (range) of 553 Austrian and Estonian boys. Statistically significant differences (by Mann-Whitney $U$-test compared) in 15 defined body sites (from neck to calf) to Estonians. Results are expressed as mean \pm SD analysed by Student's $t$-test $\left({ }^{+} P<0,05,{ }^{++} P<0,01\right.$, and $\left.{ }^{+++} P<0,001\right)$ or as median $(25$ th-75th percentile) and Mann-Whitney $U$-Test $\left({ }^{*} P<0,05,{ }^{* *} P<0,01\right.$, and $\left.{ }^{* * *} P<0,001\right)$ depending on the distribution of data.

\begin{tabular}{|c|c|c|c|}
\hline & Austrians normal weight 280 & Estonians normal weight 273 & $P$ \\
\hline Age & $11,2( \pm 0,9)$ & $11,0( \pm 0,7)$ & \\
\hline Height & $146,7( \pm 8,2)$ & $147,5( \pm 7,5)$ & \\
\hline Weight & $36,5( \pm 5,9)$ & $37,3( \pm 5,5)$ & \\
\hline 1-Neck & $2,8(2,0-3,9)$ & $1,5(1,0-2,6)$ & $0,000^{* * *}$ \\
\hline 2-Triceps & $7,3(5,9-9,0)$ & $6,4(4,8-8,4)$ & $0,000^{* * *}$ \\
\hline 3-Biceps & $3,1(2,3-4,6)$ & $2,7(1,7-4,5)$ & $0,000^{* * *}$ \\
\hline 4-Upper back & $2,6(2,0-3,6)$ & $2,2(1,3-3,6)$ & $0,000^{* * *}$ \\
\hline 5-Front chest & $3,2(2,3-5,6)$ & $3,9(2,2-6,6)$ & $0,181 \mathrm{~ns}$ \\
\hline 6-Laternal chest & $2,2(1,8-3,2)$ & $2,3(1,3-4,9)$ & $0,598 \mathrm{~ns}$ \\
\hline 7-Upper abdomen & $2,8(2,1-5,6)$ & $2,5(1,5-5,5)$ & $0,006^{* *}$ \\
\hline 8-Lower abdomen & $4,2(2,5-8,1)$ & $4,8(2,5-8,6)$ & $0,681 \mathrm{~ns}$ \\
\hline 9-Lower back & $4,7(3,6-7,4)$ & $5,3(3,2-8,2)$ & $0,901 \mathrm{~ns}$ \\
\hline 10-Hip & $3,7(2,4-6,6)$ & $4,7(2,9-7,7)$ & $0,020^{*}$ \\
\hline 11-Front thigh & $4,9(3,8-6,4)$ & $4,8(3,1-6,2)$ & $0,026^{*}$ \\
\hline 12-Laternal thigh & $6,1(4,4-7,9)$ & $5,1(3,6-6,8)$ & $0,000^{* * *}$ \\
\hline 13-Rear thigh & $4,3(3,2-6,0)$ & $4,5(2,9-5,9)$ & $0,537 \mathrm{~ns}$ \\
\hline 14-Inner thigh & $6,0(4,5-8,3)$ & $5,7(3,8-7,5)$ & $0,002^{* *}$ \\
\hline 15-Calf & $3,9(2,9-5,1)$ & $3,6(2,5-4,8)$ & $0,013^{*}$ \\
\hline BMI & $16,9( \pm 1,5)$ & $17,0( \pm 1,5)$ & $0,152 \mathrm{~ns}$ \\
\hline
\end{tabular}

values of subcutaneous adipose tissue thickness from CT, ranging from 0.9 to $47.3 \mathrm{~mm}$, was obtained. Final results were obtained by nonlinear regression $(r=0.9863)$, investigating different curve types such as polynomials from 2 nd to 5 th order, potential equations, and exponential equations. A detailed SAT profile of a subject is obtained by measuring the complete set of 15 specified body sites [12, 13].

2.3. Statistics. All statistical analyses were carried out using PASW Statistics 18.0 for Windows. Kolmogorov-Smirnov (KS) test was used to examine for normal distribution. If variables were not normally distributed, they were logarithmically transformed. Means were compared by a twotailed unpaired sample $t$-test or by Mann-Whitney $U$-Test, depending on the distribution of the data. A value of $P<0.05$ was considered statistically significant.

Discriminant analysis undertakes the same task as multiple linear regression by predicting an outcome. Stepwise discriminant analysis is concerned with selecting the most important variables whilst retaining the highest discrimination power possible. Stepwise linear discriminant analysis was applied to study whether single SAT layers or the combination of SAT layers or TBF mass could enable correct classification between Estonian versus Austrian boys.

For visual comparison, the 15-dimensional SAT-Top information was condensed by factor analysis into a twodimensional factor plot. The factor analysis shown in Figure 1 condenses the 15-dimensional SAT-Top information in a two-dimensional factor plot. Factor 1 , the $x$-axis, represents the trunk body fat development, whereas Factor 2, the $y$-axis, represents the corresponding data of the extremities.

\section{Results}

Table 1 shows basic anthropometric data of the experimental groups and the details of the Lipometer analysis encompassing Estonian (E) and Austrian (A) boys.

A discriminant analysis using all 15 SAT-Top values, $\mathrm{BMI}$, and the total body fat (TBF) in $\mathrm{kg}$ yields the following classification results: $84,6 \%$ of 553 boys are correctly classified in Estonians and Austrians selecting the body sites 1-neck, 2-triceps, 3-biceps, 5-front chest, 6-lateral chest, 7-upper abdomen, 10-hip, 12-lateral thigh, and 13-rear thigh for the discriminant function.

The factor analysis shown in Figure 1 condenses the 15-dimensional SAT-Top information in a two-dimensional factor plot. Factor 1 , the $x$-axis, represents the trunk body fat development, whereas Factor 2, the $y$-axis, represents the corresponding data of the extremities. The lower line in the figure shows the age development of healthy male controls aged from 9 (m09) to 80 years (m80). Nine-year-old boys have thin fat layers at the trunk. Near the age of 17 years, the young males typically have decreasing thicknesses of adipose tissue layers at the extremities. Between 17 and 40 years, the young males increase their fat layers on the trunk ( $\mathrm{m} 17, \mathrm{~m} 22$, $\mathrm{m} 30$, and $\mathrm{m} 40$ ). For comparison, the upper line shows the age-dependent SAT-Top development of females from 9 (f09) to 80 years (f80), respectively. 
Austrians have thicker SAT layers at the extremities (higher values of Factor 2 see Figure 1), whereas Estonians show markedly stronger fat layers at their trunks. Notably, compared to Austrians, the position of obese Estonian boys is critically nearer to male adult patients with type 2 diabetes (T2DM) and coronary heart disease (CHD) in the factor plot (Figure 1).

\section{Discussion}

In this study, for the first time, a detailed SAT-Top analysis of Austrian and Estonian prepubertal boys is presented. The results show clearly a difference of the SAT distribution in the two populations. This observation might initiate more detailed future research to characterize deviations of SAT-Top underlying populational-based diseases.

This prevalence remained high over the last 20 years. In 1990, it was estimated to be approximately three times higher than that of corresponding Swedish males in the same age group. Estonian females show approximately one-third of the mortality rate of males [24].

The importance of body fat measurements in children for the implementation of strategies to fight against the development of metabolic diseases is evident. Different approaches to ameliorate the health status of young individuals focused on body composition. Sex differences in the developing health risks from obesity are important to be included in terms of optimal risk management strategies. The incidence of obesity in boys is an upcoming growing problem in our society $[25,26]$.

The main pathologic sequels of metabolic diseases are undoubtedly driven by excess fat mass. However, the fat distribution is most probably more important than the total body fat mass [27-29]. Fat reference curves for children [9] show that boys have a relatively flat 50th centile varying between $15 \%$ and $18 \%$ body fat over the entire age range from 5 to 18 years with a peak at the age of 11 years. Variability increases up to the age of 11 years with a marked increase in positive skewness. Both skewness and variability fall after age of 11 years. Our data report directly on this critical age group of boys. Addo and Himes published new reference curves for triceps and subscapular skinfold thicknesses in US children and adolescents [30]. Especially in research settings, the SATTop determined by lipometry is an important valid anthropometric indicator of regional and total body fatness. The individual "landscape" of subcutaneous fat identified by the Lipometer is very specific for the adipose tissue phenotype caused by the interplay between genetic and environmental factors. An essential advantage of the Lipometer to other methods is the quick and noninvasive approach without radiation burden.

The few studies which have examined so far ethnic differences in adiposity in children and adolescents used advanced body composition measurement techniques with potential side effects (radiation burden) such as dual-energy $\mathrm{X}$-ray absorptiometry and densitometry [31].

Taken together, our results, achieved by a complex anthropometric analysis, identified for the first time in young male Estonians a SAT phenotype which is very similar to that of male adult patients with manifest type 2 diabetes (T2DM) and coronary heart disease (CHD). These observations may suggest a presence of a genetic risk predisposition for cardiovascular/metabolic abnormalities, which underlines the exceptional importance of early life style interventions for this population.

\section{Conflict of Interests}

All authors do not have a direct financial relation with the commercial identity mentioned in this paper that might lead to a conflict of interests for any of them.

\section{References}

[1] C. Newey, E. Nolte, M. McKee, and E. Mossialos, "Avoidable Mortality in the Enlarged European Union," ISS Statistics, pp. 7-44, 2004.

[2] C. B. Ebbeling, D. B. Pawlak, and D. S. Ludwig, "Childhood obesity: public-health crisis, common sense cure," The Lancet, vol. 360, no. 9331, pp. 473-482, 2002.

[3] U. Jaeger, K. Zellner, K. Kromeyer-Hauschild, R. Lüdde, R. Eisele, and J. Hebebrand, "Body height, body weight and body mass index of German military recruits. Historical retrospect and current status," Anthropologischer Anzeiger, vol. 59, no. 3, pp. 251-273, 2001.

[4] H. Kaur, M. L. Hyder, and W. S. C. Poston, "Childhood overweight: an expanding problem," Treatments in Endocrinology, vol. 2, no. 6, pp. 375-388, 2003.

[5] A. Pietrobelli, "Outcome measurements in paediatric obesity prevention trials," International Journal of Obesity, vol. 28, supplement 3, pp. S86-S89, 2004.

[6] A. Pietrobelli and L. Tatò, "Body composition measurements: from the past to the future," Acta Paediatrica, vol. 94, no. 448, pp. 8-13, 2005.

[7] C. Druet, K. Ong, and C. Levy Marchal, "Metabolic syndrome in children: comparison of the international diabetes federation 2007 consensus with an adapted national cholesterol education program definition in 300 overweight and obese French children," Hormone Research in Paediatrics, vol. 73, no. 3, pp. 181-186, 2010.

[8] C. Maffeis, A. Pietrobelli, A. Grezzani, S. Provera, and L. Tatò, "Waist circumference and cardiovascular risk factors in prepubertal children," Obesity Research, vol. 9, no. 3, pp. 179-187, 2001.

[9] H. D. McCarthy, "Body fat measurements in children as predictors for the metabolic syndrome: focus on waist circumference," Proceedings of the Nutrition Society, vol. 65, no. 4, pp. 385-392, 2006.

[10] E. Suliga, "Visceral adipose tissue in children and adolescents: a review," Nutrition Research Reviews, vol. 22, no. 2, pp. 137-147, 2009.

[11] R. Weiss, J. Dziura, T. S. Burgert et al., "Obesity and the metabolic syndrome in children and adolescents," The New England Journal of Medicine, vol. 350, no. 23, pp. 2362-2374, 2004.

[12] R. Möller, E. Tafeit, K. H. Smolle et al., "Estimating percentage total body fat and determining subcutaneous adipose tissue distribution with a new noninvasive optical device LIPOMETER," 
American Journal of Human Biology, vol. 12, no. 2, pp. 221-230, 2000.

[13] E. Tafeit, R. Möller, K. Sudi, and G. Reibnegger, "Artificial neural networks as a method to improve the precision of subcutaneous adipose tissue thickness measurements by means of the optical device LIPOMETER," Computers in Biology and Medicine, vol. 30, no. 6, pp. 355-365, 2000.

[14] P. S. Kaimbacher, M. Dunitz-Scheer, S. J. Wallner-Liebmann, P. J. Z. Scheer, K. Sudi, and W. J. Schnedl, "Decrease of total subcutaneous adipose tissue from infancy to childhood," Journal of Pediatric Gastroenterology and Nutrition, vol. 53, no. 5, pp. 553-560, 2011.

[15] R. Moeller, R. Horejsi, S. Pilz et al., "Evaluation of risk profiles by subcutaneous adipose tissue topography in obese juveniles," Obesity, vol. 15, no. 5, pp. 1319-1324, 2007.

[16] E. Tafeit, R. Mller, K. Sudi, R. Horejsi, A. Berg, and G. Reibnegger, "Orthogonal factor coefficient development of subcutaneous adipose tissue topography (SAT-Top) in girls and boys," American Journal of Physical Anthropology, vol. 115, no. 1, pp. 57-61, 2001.

[17] S. J. Wallner, N. Luschnigg, W. J. Schnedl et al., "Body fat distribution of overweight females with a history of weight cycling," International Journal of Obesity, vol. 28, no. 9, pp. 1143-1148, 2004.

[18] H. Niederlander, "Causes of death in the EU," KS-NK-06010EN-N, 2006.

[19] H. Mangge, G. Almer, S. Haj-Yahya et al., "Preatherosclerosis and adiponectin subfractions in obese adolescents," Obesity, vol. 16, no. 12, pp. 2578-2584, 2008.

[20] T. J. Cole, "The LMS method for constructing normalized growth standards," European Journal of Clinical Nutrition, vol. 44 , no. 1, pp. 45-60, 1990.

[21] K. Kromeyer-Hauschild, M. Wabitsch, D. Kunze et al., "Percentiles of body mass index in children and adolescents evaluated from different regional German studies," Monatsschrift fur Kinderheilkunde, vol. 149, no. 8, pp. 807-818, 2001.

[22] T. J. Cole, M. C. Bellizzi, K. M. Flegal, and W. H. Dietz, "Establishing a standard definition for child overweight and obesity worldwide: international survey," British Medical Journal, vol. 320, no. 7244, pp. 1240-1243, 2000.

[23] R. Horejsi, R. Möller, T. R. Pieber et al., "Differences of subcutaneous adipose tissue topography between type-2 diabetic men and healthy controls," Experimental Biology and Medicine, vol. 227, no. 9, pp. 794-798, 2002.

[24] H. Vides, P. M. Nilsson, V. Sarapuu, T. Podar, Isacsson, and B. F. Scherstén, "Diabetes and social conditions in Estonia: a population-based study," European Journal of Public Health, vol. 11, no. 1, pp. 60-64, 2001.

[25] M. L. Power and J. Schulkin, "Sex differences in fat storage, fat metabolism, and the health risks from obesity: possible evolutionary origins," British Journal of Nutrition, vol. 99, no. 5, pp. 931-940, 2008.

[26] J. Aucouturier, M. Meyer, D. Thivel, M. Taillardat, and P. Duché, "Effect of android to gynoid fat ratio on insulin resistance in obese youth," Archives of Pediatrics and Adolescent Medicine, vol. 163, no. 9, pp. 826-831, 2009.

[27] H. Mangge, G. Almer, S. Haj-Yahya et al., "Nuchal thickness of subcutaneous adipose tissue is tightly associated with an increased LMW/total adiponectin ratio in obese juveniles," Atherosclerosis, vol. 203, no. 1, pp. 277-283, 2009.
[28] H. Mangge, G. Almer, M. Truschnig-Wilders, A. Schmidt, R. Gasser, and D. Fuchs, "Inflammation, adiponectin, obesity and cardiovascular risk," Current Medicinal Chemistry, vol. 17, no. 36, pp. 4511-4520, 2010.

[29] F. Prüller, R. B. Raggam, V. Posch et al., "Trunk weighted obesity, cholesterol levels and low grade inflammation are main determinants for enhanced thrombin generation," Atherosclerosis, vol. 220, no. 1, pp. 215-218, 2012.

[30] O. Y. Addo and J. H. Himes, "Reference curves for triceps and subscapular skinfold thicknesses in US children and adolescents," American Journal of Clinical Nutrition, vol. 91, no. 3, pp. 635-642, 2010.

[31] S. B. Sisson, P. T. Katzmarzyk, S. R. Srinivasan et al., "Ethnic differences in subcutaneous adiposity and waist girth in children and adolescents," Obesity, vol. 17, no. 11, pp. 2075-2081, 2009. 


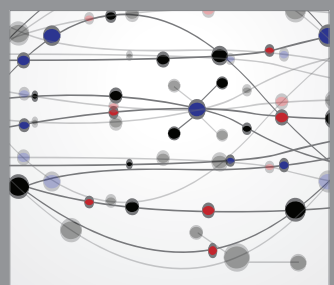

The Scientific World Journal
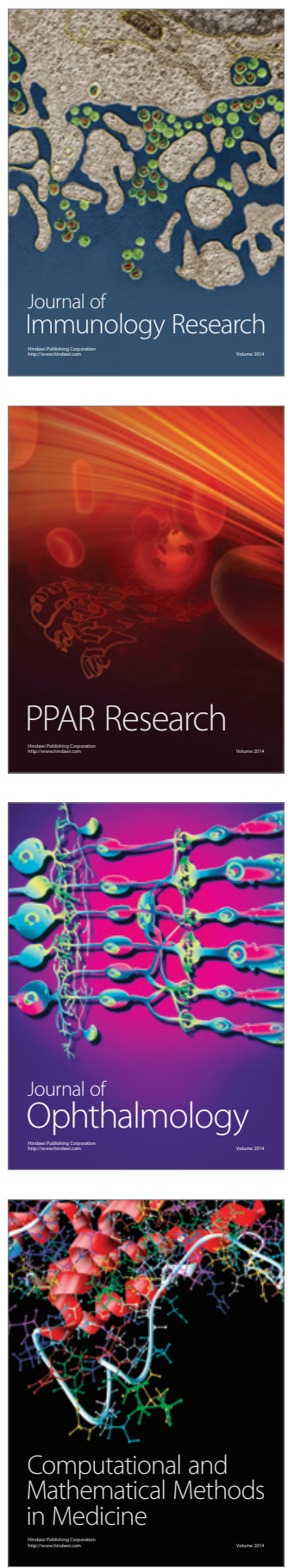

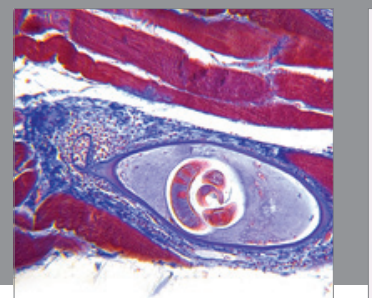

Gastroenterology

Research and Practice
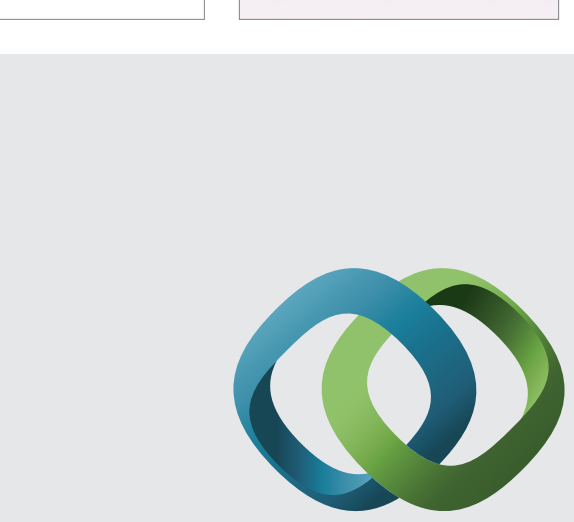

\section{Hindawi}

Submit your manuscripts at

http://www.hindawi.com
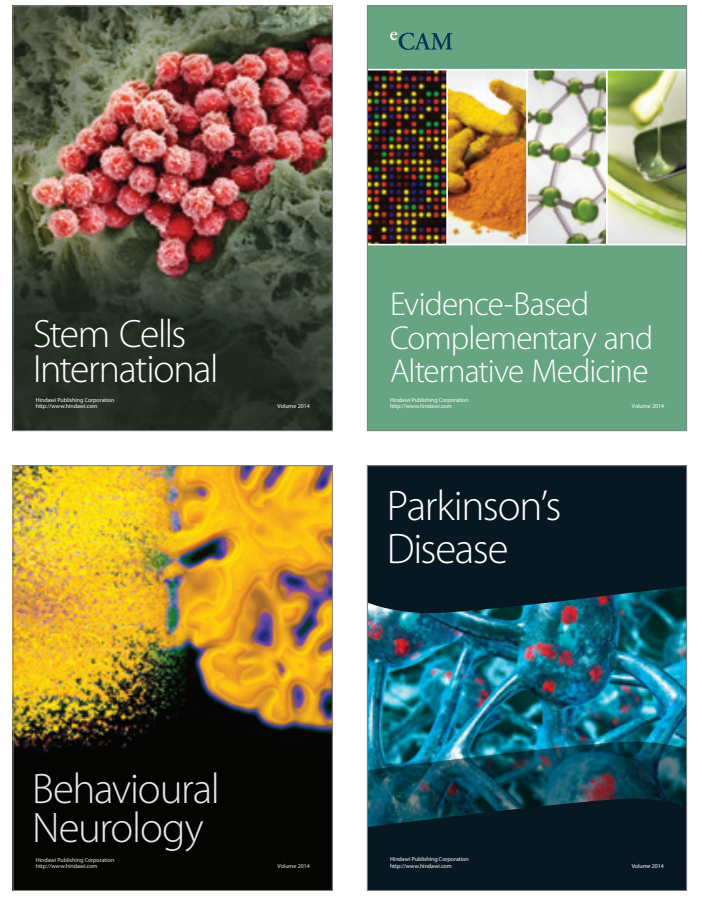
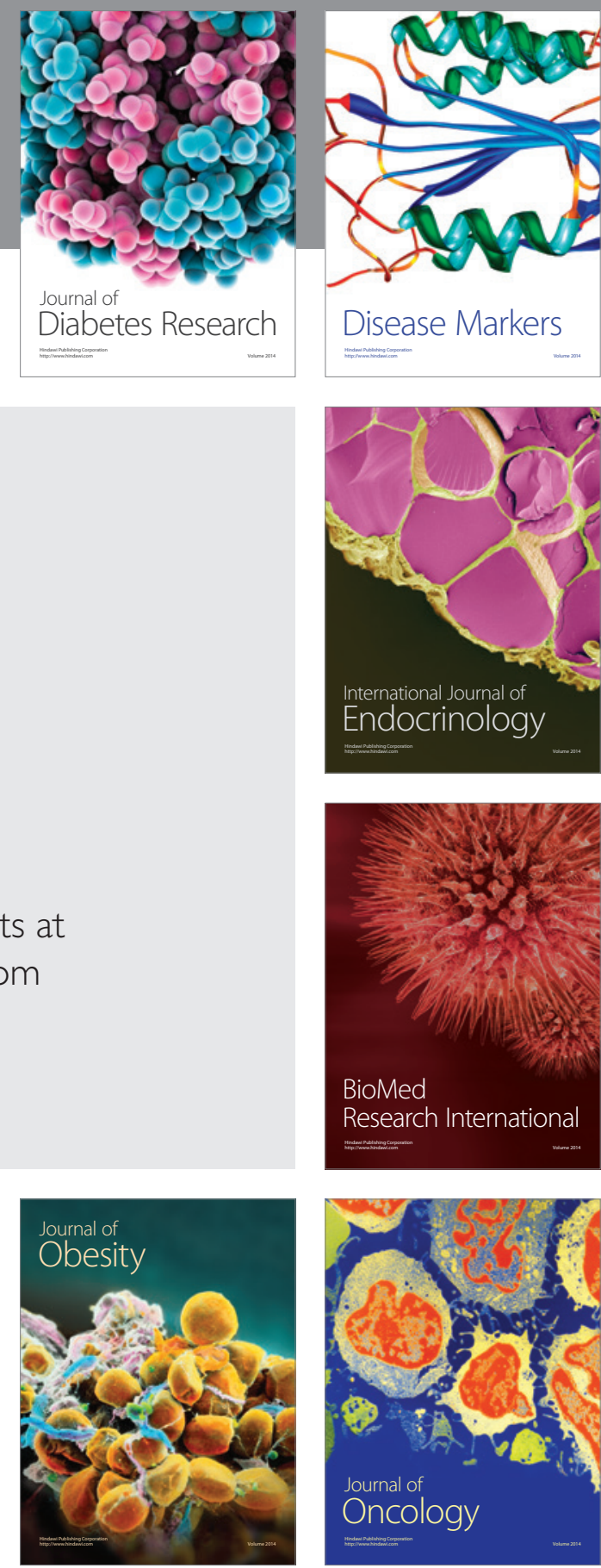

Disease Markers
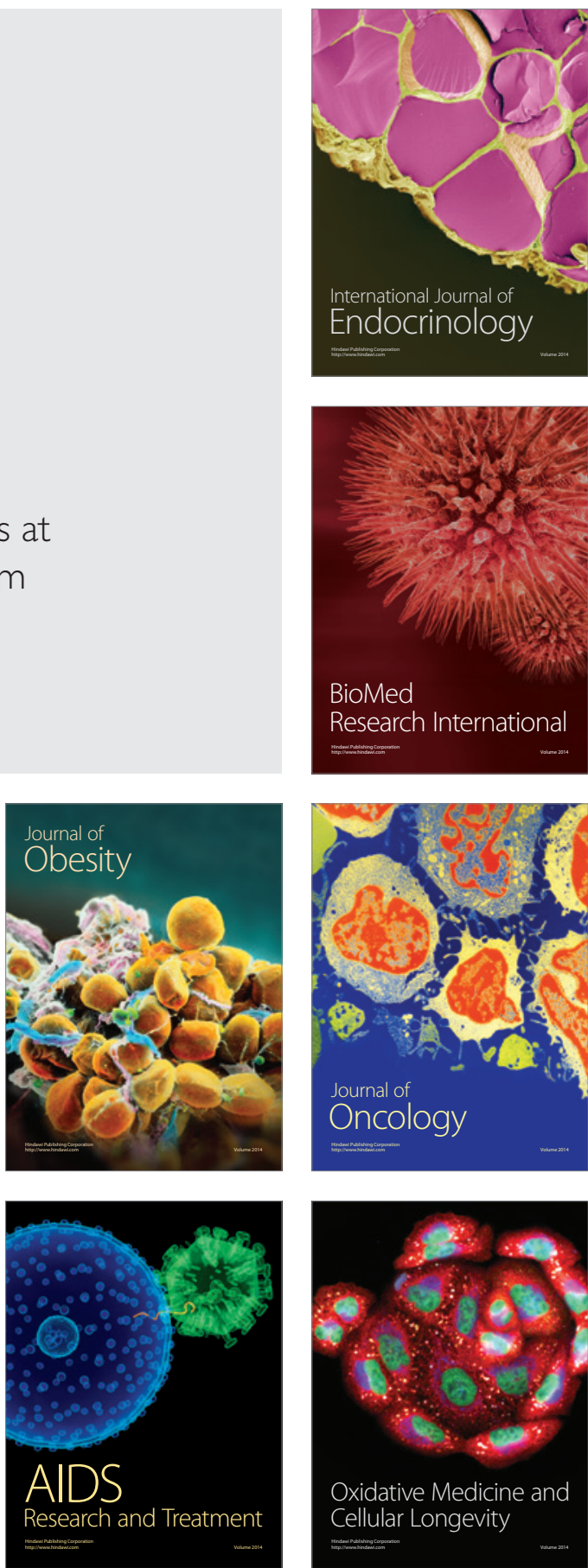